\title{
Longevity Risk from the Perspective of the ILS Markets*
}

\author{
Morton Lane \\ Lane Financial LLC, 1420 Sheridan Road, Wilmette, IL 60091, U.S. \\ E-mail: mlane@lanefinancialllc.com
}

This paper compares and contrasts the evolution of the longevity risk transfer market with the development of the Catastrophe Bond Market, more formally known as the Insurance Linked Securities (ILS) Market. The ILS market is small; the longevity market is potentially enormous. The ILS market has been around for some 15 years; the Longevity market less than 5 years. The ILS market has had a heterogeneous approach to loss measures; the longevity market has striven for homogeneity. The ILS market has used security, i.e. bond, structures; the longevity market uses derivative, i.e. swap, structures. Nearly all ILS transactions cover "event" risk; nearly all longevity structures are "aggregate". The paper reflects on these and other differences and speculates on the nature of the two approaches.

The Geneva Papers (2011) 36, 501-515. doi:10.1057/gpp.2011.18

Keywords: longevity; catastrophe; insurance linked securities (ILS); cat bonds; swaps; derivatives; mortality risk; event; aggregate

The purpose of this paper is to reflect on the development of risk transfer vehicles that are beginning to appear in the "longevity" market and to contrast them with the experience of risk transfer in the natural catastrophe market. The natural catastrophe market has used non-traditional vehicles - Catastrophe (or Cat) Bonds, a form of Insurance-Linked Security (ILS) — certainly for more than 15 years, arguably starting as far back as 1992 after Hurricane Andrew. The longevity market is newer, in that ILS-like longevity risk transfer only began some three years ago. The concept of transferring longevity risk has been around somewhat longer but early experiments did not meet with immediate success. One question is, therefore, in what ways are these two markets different and what lessons can one market learn from the other?

\section{Preliminaries and definitions}

First, some words about longevity, mortality and life settlements are in order. Broadly defined we are talking about the financial risk or the financial consequences coming from actual life spans turning out to be longer than expected. Obviously life can be shorter than expected or longer than expected. Both can have financially adverse

\footnotetext{
* Based on a presentation and panel remarks originally given at the Sixth International Longevity Risk and Capital Markets Solutions Conference held at the Swiss-Grand Resort and Spa, Bondi Beach, Sydney, Australia, 9-10 September 2010.
} 
consequences. Life being shorter than expected is sometimes referred to as premature death, or mortality risk. Conversely when life is longer than expected it is often referred to as longevity. A provider of life insurance policies expects his insured population to die at generally predicted (expected) rates. The life insurer is affected adversely financially when mortality rates rise and the insured populations must be paid death benefits prematurely - mortality risk. A provider of pensions or annuities is affected when the life experience of an endowed population is longer than expected. Payments must continue much longer than anticipated. This is known as longevity risk. Clearly mortality and longevity are related. When mortality rates decline longevity rates will tend to rise, and vice versa.

In the securitisation world, there have been successful issues of mortality bonds going back some eight years (Swiss Re's Vita Capital is the most frequent issuer). It is the longevity risk which has only seen recent deal success. This is the subject of the present paper, although the mortality experience is quite germane and will be discussed further below.

One area that will not be discussed herein is life settlements. It is nevertheless an important sub-division of the mortality and longevity spectrum of risks. One can think about mortality and longevity risks as institutional "wholesale" risks; life settlement risk is more "retail". Life settlements are the securitisation of specific groups of life insurance policies which are sold by insureds to third-party investors. One way to think about this whole process is to start with the concept that an individual taking out a life insurance policy is transferring his mortality risk to longevity risk. He is afraid of premature death and wants to protect his family or dependents against the adverse financial consequences to them. In exchange for that protection he contracts to pay a lifetime stream of premiums to secure that death benefit for his beneficiaries. The life insurance company is the entity that assumes his mortality risk. At some point his dependents may no longer be dependent and he may want to surrender his policy - to get rid of his assumed longevity risk - that is, paying premiums till death - and consume part or all of his policy's value. Life settlements is the business of selling that life policy, its benefits and its obligations, to third parties. They, the third-party investors, are then assuming the individual's longevity risk-paying a stream of premiums in exchange for death benefits. For investors to assume the risk they have to decide that the present value of the death benefit is greater than the present value of the premium stream they are assuming.

The same calculus is, of course, the one the insuring company would make in calculating "surrender value". Except that the calculus results turn out to be different. It appears that surrender values are typically lower than investors (and insureds) think they should be. Hence there is an opportunity for investors to buy policies from insureds and assume their longevity risk. If surrender values were greater than or equal to the investor perception of the risk, the market would not exist.

There are a host of issues related to life settlements that include legal risks (many have been challenged in court), insurable interest (not all states allow transfer) and the behaviour of bad actors (recent court cases speak of this) which complicate their evaluation, but the essential economic message of life settlements is that there is a price gap between life insurance company surrender values and investor perceptions of economic value. As long as that gap exists, life settlements activity will continue.

The significance of this market is that it potentially exposes prices at which insureds are prepared to give up their longevity risk, and, more importantly, the price at which 


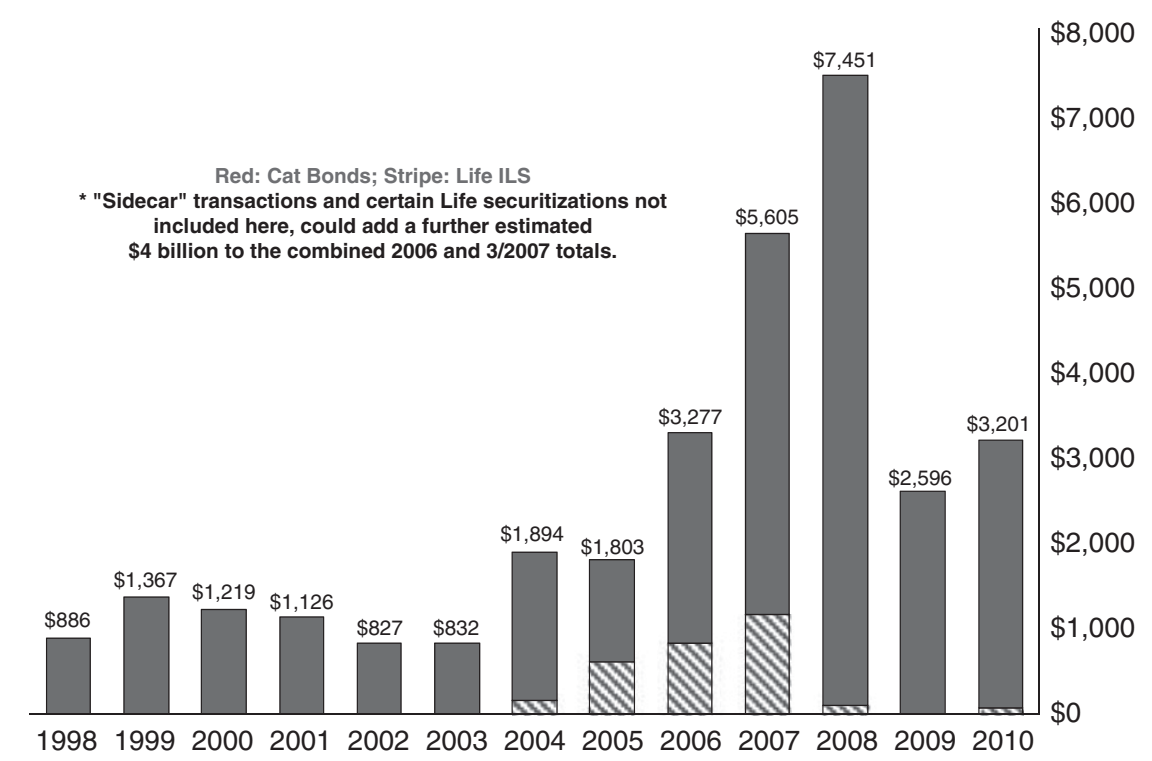

Figure 1. Total ILS issuance (1998 to Q1/2010) (in US\$).

investors are prepared to assume it. As we will see in the longevity swap market, price transparency is limited; it is well to remember that the life settlement market may be another source of price information.

\section{The ILS market}

To view the longevity securitisation efforts from an ILS point of view requires some perspective.

The natural catastrophe market is small relative to the life market. Examining the financial statements of natural catastrophe insurers indicates that the capital devoted to natural catastrophes is arguably US\$200-US\$300 billion. The capital of the life markets is in the multiple trillions, so that in one sense it is presumptuous to view longevity risk securitisation from the ILS perspective. That acknowledged, there are many important observations to be made.

Total accumulated issuance of ILS in the past 15 years is approaching US\$40 billion, and approximately US\$12 billion of ILS are presently outstanding ${ }^{1}$ (Figure 1 indicates annual ILS issuance). These numbers include any security that was issued with a "risk analysis" as part of the offering circular. The analyses are provided principally by three firms, Air-Worldwide, RMS and EQECAT, although some transactions are provided with private analyses. In all cases the investor has some third-party estimate of expected loss. Ninety per cent of the accumulated issuance

\footnotetext{
${ }^{1}$ Unless otherwise noted, the source for data in this paper is Lane Financial LLC. Access is available on www.lanefinancialllc.com.
} 
covers natural hazards such as hurricanes and earthquakes. Nearly 10 per cent of issuance has covered extreme mortality which we return to later.

The natural catastrophe securitisation market started after Hurricane Andrew in 1992. The natural catastrophe reinsurance market was a market that needed capital and was prepared to experiment with any means of raising that capital. The market was born out of disaster and the consequent commercial necessity. It is a pattern by which it has advanced ever since.

Its first incarnation was at the Chicago Board of Trade where "cat options" introduced at the end of 1992. That experiment lasted five years and captured enough of participants' imagination to be copied or mimicked in New York, Bermuda, London and Chicago a second time. None of these exchanges has (robustly) succeeded, but two are still in existence with active open interest. It is not clear what prevents them from success but perhaps the futures exchange format of high turnover, continuous auctions is too liquid for the slow moving business of insurance. ${ }^{3}$ The economics of each is different. In addition, in the case of the Chicago Board of Trade's first attempt, the market also died after a prolonged soft market at the end of the 1990s. This caused prospective investors to lose interest; returns were better elsewhere.

During these repeated exchange attempts there was also genuine experimentation. Consider that at the exchanges contracts were introduced which were based on the following list of loss measures:

1. Loss ratios in the underlying exchange contract;

2. $\mathrm{PCS}^{4}$ Industry Loss (by region and proportionate to loss);

3. Guy Carpenter's (customizable) loss ratios;

4. PCS loss estimates (by region and event);

5. Hurricane Index formula (based on storm intensity).

These are some of the experiments that have taken place just on exchanges. The other, more successful, part of catastrophe securitisation is the ILS market. It, too, is replete with loss measure experiments. Consider that most issuers would prefer to issue bonds on an indemnity basis and that most investors want ILS issued on a non-indemnity index-like basis. The index-like measures that have been tried are loss indices based on:

1. Sigma $^{5}$ Reports;

2. Munich Re Nat Cat Service reports;

3. PCS industry numbers;

4. Weighted PCS numbers;

5. PERILS ${ }^{6}$;

${ }^{2}$ Cat options are derivatives rather than securities, but may be considered the intellectual forerunner to Cat ILS.

${ }^{3}$ Coincident with this writing, the CME Group in Chicago has, surprisingly, rejected the trading of swaps at the CME on somewhat similar arguments, that is, that swap and futures trading have different turnover rates and different economics.

${ }^{4}$ Property Claims Service is an industry entity that measures event losses for the (U.S.) industry as a whole.

${ }^{5}$ Sigma is a Swiss Re subsidiary that reports annually on worldwide losses.

${ }^{6}$ PERILS is an index designed by a consortium of European Insurers who are trying to replicate an improved version of PCS for European losses. 
6. Wind Speeds;

7. The Richter Scale;

8. Paradex $^{7}$;

9. AIR modelled loss (now Verisk);

10. Computer replications of cedant's book of business.

This list is not intended to be comprehensive, and new developments appear regularly in the market. The point is that the experiments continue; specific indices are clearly not the determinants of overall success.

One is reminded of the title of a book by Lance Armstrong, the seven time Tour de France winner and cycling great, "It's not about the bike". So it would appear it is with ILS, "It's not about the index". To be sure index measures are important and vital and experimentation will surely continue, but index measures in themselves will not provide the tipping point between success and failure of a market.

The LLMA, ${ }^{8}$ the longevity market trade body, has designed and been active in promoting index measures and trying to standardise practices to promote the longevity market. Such design and suggestion is very desirable, but it is well to keep in mind, if you observe the above, that "It's not about the index". It's about commercial necessity. The growth of the ILS market has (a) never had a trade body, and, (b) has no standardised loss measure. Instead it has grown in fits and starts as individual brokers, cedants and investors compete for capital, return and ideas. In some circumstances it is almost as if any index will do. Following the devastation that hurricanes Katrina, Rita and Wilma did to the Gulf of Mexico drilling industry, insureds were prepared to pay very high premiums for an index design called "cat-inthe-box". In this, any storm of the requisite strength traversing a latitude and longitude determined box would trigger a payment. In 2006 such cover was a necessity-no other protection was available. But in subsequent years such covershowever improved - have been unsalable.

Finally, in the ILS market, despite investor desires otherwise, approximately 20 per cent of the issuance has remained indemnity based. In the longevity market, in contrast, most deals appear to be stubbornly indemnity based.

\section{Event-based}

Another observable difference between the catastrophe bond segment of the ILS market and the emerging longevity market segment is that nearly all catastrophe bonds are occurrence or event based. The longevity swaps listed in Table 1 appear in contrast to be trend based, that is, the change in longevity from historical levels. To be sure, an event will affect these swaps, possibly dramatically, but the object of the swap appears to be to smooth results rather than absorb losses. Indeed it is not clear what the event to affect longevity would be: a sudden cure for cancer, a diabetes pill, outlawing smoking in restaurants?

\footnotetext{
${ }^{7}$ An index designed by RMS for measuring wind speed losses.

${ }^{8}$ The Life and Longevity Market Association.
} 
Table 1 Market for hedging longevity risk has rapidly expanded

\begin{tabular}{llccc}
\hline Date & Hedger & Size $(\mathrm{mm})$ & Format & Term \\
\hline $\begin{array}{l}\text { Developments } \\
\text { in the longevity hedging market }\end{array}$ & Not disclosed & Derivative & 10 years \\
Jan 2008 & Lucida (Insurer) & $£ 500$ & Derivative & 40 years \\
Jul 2008 & Canada Life (Insurer) & $£ 1,500$ & Insurance & Run off \\
Feb 2009 & Abbey Life (Insurer) & $£ 475$ & Derivative & 10 years \\
Mar 2009 & Aviva (Insurer) & $£ 1,200$ in total & Derivative & 50 years \\
Jun 2009 & Babcock International (x3) (Pension Fund) & $£ 1,900$ & Insurance & Run off \\
Jul 2009 & RSA (Pension Fund) & $£ 1,000$ & Insurance & Run off \\
Dec 2009 & Royal County of Berkshire (Pension Fund) & $£ 3,000$ & Insurance & Run off \\
Feb 2010 & BMW U.K. (Pension Fund) & $£ 1,300$ & Insurance & Run off \\
Jul 2010 & British Airways (Pension Fund) & & &
\end{tabular}

Source: J.P. Morgan.

Even in the case of the early mortality bonds first introduced by Swiss Re in 2003 an extreme event was probably behind their introduction. While not articulated by the company in its issuing specifications, the risk analysis attached to the bond made it clear that the extreme jumps in mortality covered by the bond could be caused only by the explosion of terrorist dirty bombs in major cities, or the onset of a 1918-style pandemic. These were extreme events, that is, occurrence risk. The terrorist attack of 9/11 was in 2001 and the first SARS outbreak was in 2002; motivation indeed to get protection in 2003.

Approximately 90 per cent of all ILS are event risk-based. ${ }^{9}$ They are risk transfer instruments. Furthermore, the motivation to get rid of the risk, or protect oneself from its effects, does not appear to have been driven by direct regulation. Early issuers of ILS were offshore reinsurance companies not subject to specific regulations. They were, however, driven to protect themselves because of their own analysis or by that of rating agencies.

\section{Regulatory initiatives}

The statistics on actual transactions in the longevity sector are closely held. That is as might be expected. It was true of the ILS market when it first started. However, what glimpses there are into the catalogue of early deals shown at conference presentations often show that the typical cedants are from the U.K. and the swap counterparties tend to be European. Now we know that the U.K. regulators ${ }^{10}$ have made a point to ensure that pension funds recognise their true liabilities. This has precipitated U.K. pension providers to either get rid of risk, smooth unwanted volatility or raise capital. It seems that most have opted for the middle course - no surprises.

\footnotetext{
${ }^{9}$ The other 10 per cent of issued ILS deals involve aggregate cat risk and certain aggregating risks like Auto or Medical Liability.

${ }^{10}$ The Pension Regulator, U.K. government entity.
} 
One could also argue that the geography of the two sides to the transaction is motivated by differential regulation. European regulators have not been so insistent on pension liability recognition as U.K. regulators. Is this an example of regulatory arbitrage, rather than true risk transfer where both sides have the same incentive landscapes? Furthermore, most of the counterparties indicated in Table $1^{11}$ have been within the insurance market. A minority of the deals have bridged the gap from insurance market to capital market. As far as the ILS market is concerned some fraction (10 per cent?) of ILS issued by the insurance market is bought by other insurance market participants. Early on the amount bought by inside-market participants was admittedly higher; nowadays the vast majority of ILS issues are bought outside the insurance market by capital market funds. Also the fact that the issuance of ILS has been done by insureds, reinsureds and retrocessionaires (all the participants in the traditional risk transfer chain) suggests that no regulatory arbitrage appears to be taking place. Indeed the geographic diversity of buyers and sellers of ILS underscores the point.

All this may change as Solvency II wends its way into effectiveness and as it harmonises regulation. All pension and annuity providers may want to get rid of risk (or raise more capital) and the market may well become deeper, bigger and tremendously important, which is all well and good. At the moment, the observation is that the longevity market is being born by force of potential regulation, not selfrecognition, the way the ILS market appears to have been.

\section{Swaps not bonds}

As we have already observed, most known longevity deals are either in the form of swaps or insurance. Few are in bond form and those have been most difficult to place. ${ }^{12}$ This provides an interesting point of comparison between longevity and ILS markets.

Insurance or swap transactions involve counterparty risk. ILS markets have avoided counterparty risk, at least since their scare with the Lehman default. Prior to the Lehman default, ILS deals involved swap counterparty risk-supposedly fully collateralised. Both counterparty and collateral were found to be wanting. Four transactions where Lehman was counterparty suffered substantial losses from the default because of poor collateral quality.

Since then, 90 per cent of all ILS transactions have had no swap counterparty and all collateral has been invested in government guaranteed securities. Even where swaps have been used, the collateral requirements have been very stringent. In contrast, longevity deal investors seem to still feel comfortable with collateralized counterparty swaps as the appropriate form for longevity risk transfer. What is not evident is whether the restrictions on collateral have been tightened, post 2008, in the same way that the ILS market responded.

\footnotetext{
${ }^{11}$ Table 1 courtesy of Guy Coughlan, Managing Director, J P Morgan, and Chair of the LLMA Technical Committee.

${ }^{12}$ Blake et al. (2006) chronicle one important early bond experiment by BNP and reviews many of the obstacles and issues.
} 


\section{Term}

One small but noticeable difference in ILS and longevity deals is the term of the deal. Perhaps inevitably longevity deals are longer in term than ILS. The average issue term for ILS is around three years. The longest has been ten years and some have been as short as seven months. Investors don't seem to be comfortable with longer exposures. Or perhaps cedants don't know what their book is going to be beyond two to three years.

In a fascinating consequence of issuance through hard and soft markets, it is also true that ILS deals will tend to be shorter term in hard markets and longer in soft markets. Whatever average term the longevity market lands on, it will be interesting to see whether such behaviour will be replicated in longevity issuance. One would expect so.

One reason that ILS investors prefer shorter deals is that they want pure insurance risk. When deals get longer, such as in closed book life deals, they will tend to involve interest rate risk. Investors don't need interest rate risk, they have plenty. Longevity deals will need to try to separate the interest risk from the pure longevity risk.

\section{Price transparency}

As with so much in the longevity arena, the price of risk transfer is still not well known to outside observers. The secondary market does not exist and primaries are reluctant to reveal deal details while the market is small and they can maintain a competitive edge. This is also necessarily a consequence of being a swap market. Most swaps are (a) over the counter and (b) one-to-one. The price of the deal remains known only to the two parties.

The bond model allows for distribution to multiple parties and necessarily leads to more price transparency. Even though the ILS market is a private placement market, prices become well known and disseminated. The swap or even reinsurance of risk transfer does not lend itself to disclosure of prices. Furthermore, both forms make it difficult to disentangle the "price-relative-to-risk" basis common in ILS. One example of this is the absence of rating for longevity swap deals. Without the rating, investors have less information even than they get with corporate bonds and that is a detriment to widespread adoption.

\section{Government-issue longevity bonds}

Promoters of longevity bonds think that it is vital to get the market started, not least because it would reveal pricing of longevity risk. Some have argued that it in the interest of governments to help start the market. They could do this by "issuing" bonds to the market and thereby setting an example and being a catalyst.

Approached with an ILS mindset in its most general concept form, a longevity bond would involve the payment of an amount by the investor which would be held in trust and invested. If longevity was as expected or lower, the investor would get his funds returned. If, however, longevity increased beyond expectation, the funds would be used to pay the issuer of the bond and would thus form a loss for the investor. The issuer of the bond is selling longevity risk, that is, buying protection; the bond buyer would be offering protection, that is, assuming risk for a price. 
An alternative formulation of this concept of a longevity bond has been proposed by David Blake. ${ }^{13}$ In this he suggests that, stripped to its essentials, a bond could be issued where the buyer would receive not a return of principal but a deferred stream of interest payments coincident with some period of longevity exposure. The size of the coupon would be determined by the size of the remaining population cohort still living, the surviving population, relative to the size of the population expected to be living at the coupon date. In other words, if longevity rose, survivorship would rise, coupon payments would increase and the bond holder would receive funds via increased coupons to defease his unanticipated risk.

In this formulation the "issuer" is providing protection rather than receiving it. Blake draws the parallel to inflation-linked bonds where the government, as issuer, provides inflation protection. Clearly care must be taken in articulating these concepts in terms of buying and selling. As observed, in the ILS space the issuer is the buyer of protection; the investor is the protector. In a new market like longevity there is often a confusion of terms that needs to be settled. Blake's formulation could easily be switched to conventional terms by linking the coupon payment proportionate to the non-surviving population rather than the surviving population. We suspect that over time the labelling of deals will gravitate to conventional use where what you are "buying" and "selling" is risk.

Whatever formulation is used, Blake's or a more conventional bond structure, the market has to accept the concept and be adequately rewarded for the perceived risk. Based on the precedents set in the ILS market it could be expensive, see following discussion. The important point, however, is whether a demonstration effect by a government bond would be catalytic. It is impossible to say with any confidence; however, what can be stated (with certainty) is that government issuance was not needed in the catastrophe market. The ILS market grew (albeit slowly) without any government demonstration issue. It was ten years before any government used the market. Since the first "governmental" use of the market, arguably by the Taiwan Residential Earthquake Insurance Pool, the market has been used by Mexico (twice), The World Bank (in the Caribbean), and North Carolina and Massachusetts Wind Pools. However, and this is the important observation to make, in no case was it for demonstration purposes to stimulate the market. Instead in each case the governmental entity used the market that existed to gain protection.

The suggestion of government demonstration ${ }^{14}$ would perhaps be more convincing if the government were to be buying protection itself. Most focus is on the U.K. government but the comment is apropos for all governments. They all have a social security scheme which means that they have already got longevity risk. "Issuing" longevity bonds as Blake proposed is tantamount to adding to that risk. Such a demonstration issuance would be bought by pension plans or annuity providers,

${ }^{13}$ Professor David Blake is a director of the Pensions Institute, Cass Business School and his joint work on this subject, with Tom Boardman and Andrew Cairns, was also presented at the Sixth International Longevity Conference in Sydney.

${ }^{14}$ It is often cited that it required a government initiative and demonstration to get the inflation protected market off the ground. The U.K. 1981 initiative did indeed lead to widespread use by the U.K. and other governments, but private inflation-protected bonds remain a small part of the overall market. 
Table 2 Summary of mortality ILS issuance

\begin{tabular}{|c|c|c|c|c|c|c|c|}
\hline & $\begin{array}{c}\text { Total } \\
\text { issuance }\end{array}$ & $\begin{array}{l}\text { Extreme } \\
\text { mortality }\end{array}$ & $\begin{array}{c}\text { Embedded } \\
\text { value }\end{array}$ & $\begin{array}{c}\text { Spread- } \\
\text { mortality (\%) }\end{array}$ & $\begin{array}{l}\text { Spread - emb. } \\
\text { value }(\%)\end{array}$ & $\begin{array}{c}\text { Exp. loss- } \\
\text { mortality }(\%)\end{array}$ & $\begin{array}{l}\text { Multiple- } \\
\text { mortality }\end{array}$ \\
\hline \multicolumn{8}{|l|}{2002} \\
\hline 2003 & 400,000 & 400,000 & & 1.35 & & 0.02 & \\
\hline \multicolumn{8}{|l|}{2004} \\
\hline 2005 & 952,000 & 362,000 & 590,000 & 1.45 & 0.71 & 0.06 & 22.6 \\
\hline 2006 & 852,424 & 852,424 & & 1.82 & & 0.13 & 14.5 \\
\hline 2007 & 629,152 & 629,152 & & 0.30 & & 0.03 & 9 \\
\hline 2008 & 100,000 & 100,000 & & 1.35 & & 0.05 & \\
\hline 2009 & 75,000 & 75,000 & & 6.50 & & 0.46 & 14.1 \\
\hline 2010 & 50,000 & 50,000 & & 5.25 & & & \\
\hline Total & $3,058,575$ & $2,468,576$ & 590,000 & 1.50 & 0.71 & 0.08 & 18.7 \\
\hline
\end{tabular}

Note: Total coupon consists of the spread plus a fixed rate component.

thereby transferring risk to the government, effectively nationalising pension plans. If instead the government were to try to buy protection in the market, as has been done in the ILS markets, they soon learn the market cost of their exposure and would perhaps be motivated to mitigate the risk by raising retirement ages, benefits, etc. The argument could be made that governments can't afford to buy protection - they are broke. That may be so but under existing schemes, social security funds are invested in their own paper via Treasury Bills; redeploying part of that to buying longevity bonds would go a long way to showing the true cost of such schemes.

\section{Mortality bonds}

Table 2 and Figure 2 contain two important pieces of information about ILS and mortality bonds and relevant to a potential longevity bond market. The table shows the total issuance of mortality bonds over the last eight years. Earlier we referred to possible motivations for the start of mortality bonds by Swiss Re in 2003 (pandemics and dirty bombs). That motivation apparently continued more or less until the present. In all $\$ 3$ billion mortality bonds have been issued including approximately $\$ 600$ million of embedded value deals. ${ }^{15}$ The average coupon paid to investors is 1.50 per cent and the average expected loss in the risk analyses is 0.08 per cent.

This pricing may come as a shock to some. It will to those embracing "fair pricing" rather than market pricing. The record says that investors have required a premium of 18.7 times the expected loss $(1.50 / 0.08)$ to accept the risk of sudden jumps in mortality experience. Now early on some of this could have been dismissed as novelty premium,

\footnotetext{
${ }^{15}$ Embedded value deals include bonds based upon closed books of life policies. Strictly these deals have not always provided a full risk analysis to investors, but have offered investors a range of expert scenarios, about mortality and lapse rates, etc. The investor is then left to attach his own probabilities to the scenarios to complete the risk analysis.
} 


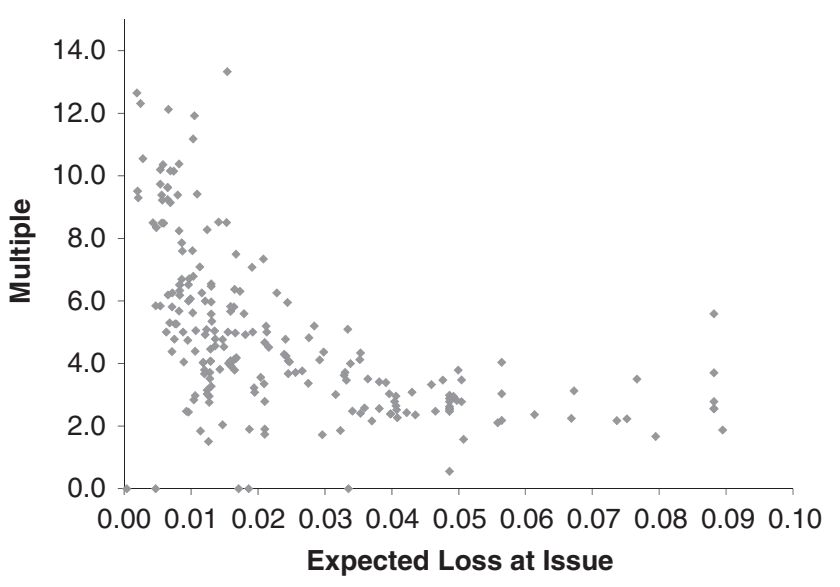

Figure 2. Multiple of expected loss on all ILS issues vs. expected loss (2004 to Q2, 2010).

but high multiples of expected loss have persisted in recent deals. Indeed, Figure 2 shows the multiple required of all ILS ever issued since 2004 whether cat or mortality. Low expected losses require high multiples, but even if the expected loss on the deal is high (say in the 5-8 per cent range) the market still requires a multiple of two or more.

Cedants getting rid of longevity risk to the capital markets can expect to pay similar high multiples if the ILS market is any guide. Perhaps they are already paying such multiples in the swap or reinsurance deals already consummated, but without a visible independent risk analysis it is hard for an outside observer to say. Indeed, one could argue that the whole swap format obscures the expected loss/multiple insight on which ILS investors have come to rely.

There are other features of the ILS bond format that the issued mortality bonds have experienced. Most prominently the mortality bonds trade in a secondary market with attendant benefits and consequences. We trace out some of those in Figures 3-5.

Figure 3 shows the total return ${ }^{16}$ an investor would have experienced between 2004 and the second quarter of 2010. Investors in every cat ILS would have gained an average annual return of 8.02 per cent. Investors in all mortality bonds from Figure 3 would have experienced an average annual return of 4.439 per cent. The point to make is not the relative magnitudes of return (adjustments have to be made to put it all on a comparable basis) but how similar the variation in return is one month to the next over the seven-and-half-year period. Evidently, even though one series is cat and the other is mortality, they are broadly affected by the same capital market trends.

Figure 4 isolates one adjustment that needs to be made: the financing component of return. During most of the period shown, the bonds were priced to LIBOR plus a fixed spread. To get to the insurance return, that LIBOR or financing must be subtracted out. Awkwardly, during this period the Lehman Bros. default and the bonds to which

${ }^{16}$ The total returns measured here are based on the LFIRI index of Lane Financial LLC. Methodology is described on the website ( $w w w$.lanefinancialllc.com). Suffice it to say here that the index is market cap weighted and rebalanced monthly, similar to the S\&P 500 stock Index. 


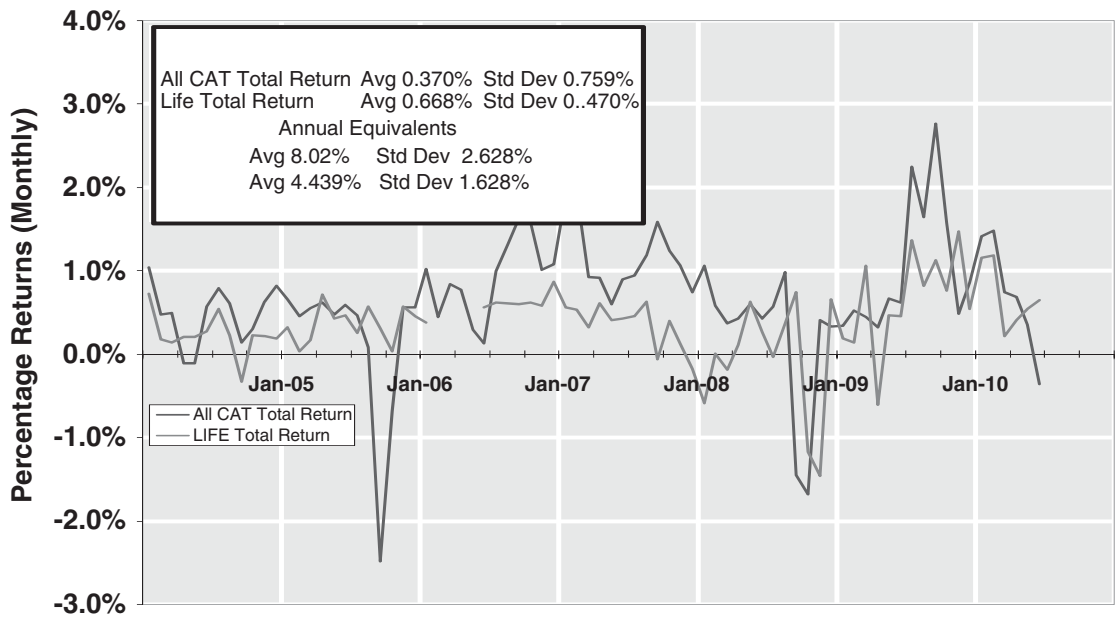

Figure 3. Monthly all CAT ILS and Life total return performance (2002 to Q2, 2010).

they were counterparty suffered large losses. In the LFIRI index series those losses were allocated to the financing cost and are represented in the spike down in Figure 4. Net of the respective financing costs the "insurance" returns for cat and life investors is shown in Figure 5. Clearly the two series move closer together. ${ }^{17}$

The one period where the two series do appear to depart from each other is from mid-2007 to mid-2008. This is the circled period in Figure 5. Here something was affecting the life market above and beyond what was affecting the cat market. It was the H1N1 scare. During that period swine flu, as H1N1 is popularly known, was detected in the Philippines. The market in mortality bonds fell; total return dropped as investors feared that a swine flu pandemic would lead to a jump in observed mortality over the next few years. The outbreak did not spread or have the dire consequences that some feared and mortality bonds were gradually bid back up.

The point here is that the secondary market is sensitive to real-world happenings even in markets as tiny as the mortality bond market. Anyone thinking about the cost of issuing a mortality bond in 2007 would know that the cost was going to be substantially higher than previously. They could have guessed that given the knowledge of the outbreak, but here was a quantification of the amount. At the same time issuers at other periods would have been able to gauge both welcome and unwelcome news from the secondary markets. All bonds were in bad odour in the fall of 2008; all bonds, mortality or no, were in high demand in the fall of 2010 . When longevity or mortality is truly part of the capital markets they behave as capital market instruments.

\footnotetext{
${ }^{17}$ Two other comments are appropriate. First the issuance range of cat ILS is typically BB rated whereas the life ILS are AA rated so returns in one will necessarily be higher. The second comment is that the life ILS market is often very thin and prices from one month to the next can be erratic. We have qualified our return series with this comment on the website. Thus the trends capture effects better than single month observations.
} 


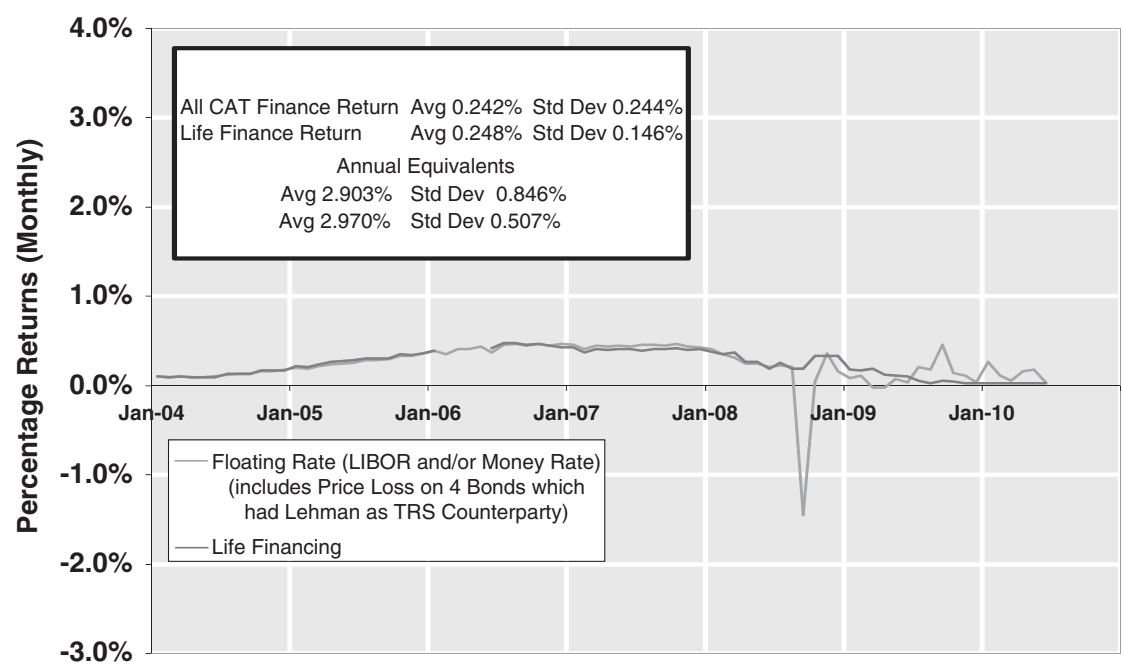

Figure 4. Monthly all CAT ILS vs. life finance return performance (2004 to Q2, 2010).

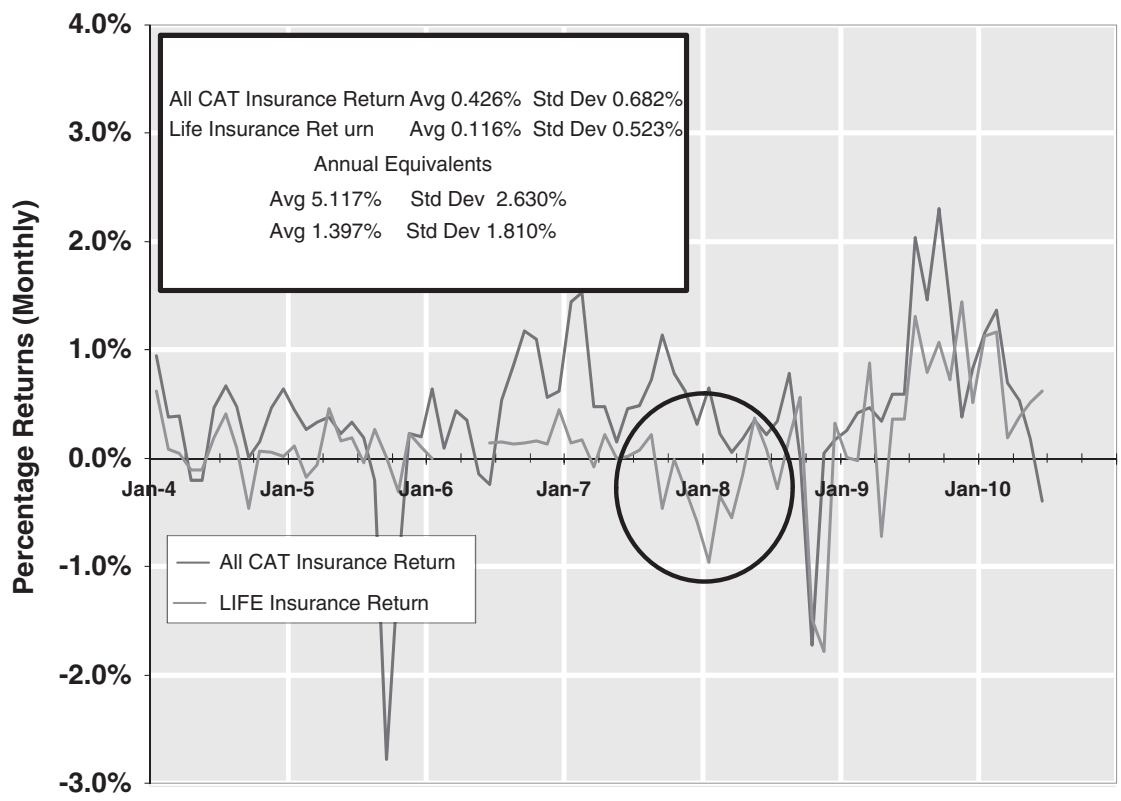

Figure 5. Monthly all CAT ILS vs. life insurance return performance (2004 to Q2, 2010).

At this writing another bond from Swiss Re, Kortis Capital, is in the market. It is a small issue but it is an important experiment. We have earlier observed that mortality and longevity are related, although not isomorphically. Thus, higher mortality results in lower longevity, and vice versa. Further, investors, as we have seen, have accepted 
bonds based on higher than expected mortality. The Kortis bond explores the other side, whether investors will buy bonds based on falling mortality (and hence rising longevity). Intriguingly the longevity risk in the Kortis bond is expressed as the difference in life expectancy of two different cohorts - essentially the U.K. "golden" cohort and the U.S. baby boomer cohort. ${ }^{18}$ The rationale of the bond may be described as follows. Swiss Re sells a lot of life policies in the U.S. to a preretirement population-boomers. It also sells, or has exposure to, annuities for an older population in the U.K. A bad outcome for Swiss Re would therefore be a rising mortality in the U.S. (a pandemic?) and rising longevity in the U.K. (cure for cancer?). But both these outcomes are related - a pandemic will affect the U.K. as well resulting in falling longevity; ditto the cure for cancer. So the Kortis bond hedges against the difference in the two indexes resulting from a movement in either or both sides. Options traders might view this as analogous to Swiss Re buying a straddle, but not quite. The outcomes on either end are related but not either one end or the other, as a straddle would be.

The success of the Kortis issue will answer the question of whether investors will venture beyond their average ILS horizon of three years. Kortis is a six-year exposure bond. The likely answer to this and the acceptability of longevity questions is, yes. As a result a new and in many ways a more transparent division of longevity risk securitisation will be born.

Another longevity hedge enacted post writing of this paper was the longevity hedge executed by Pall Corporation in January 2011. In a first, it covered its deferred (preretirement) pension plan members. It also used an index hedge, establishing another advance of the "forms" of longevity risk transfer.

\section{Concluding remarks}

From the perspective of the ILS markets the search for longevity risk transfer seems to be taking a different path from the more organic growth history of the ILS market. There appears to have been a push from regulators to address the risk, at least in the U.K. There is more emphasis on standard setting and good practice among the members of the organised trade association, the LLMA. Many of the LLMA members are counterparties to deals that appear to have been done to date. Indeed, given the domiciles of cedants and counterparties in the association there is the suggestion of regulatory arbitrage rather than true economic demand. This push, however, may end up being given truer legitimacy by the introduction of Solvency II for all ${ }^{19}$ in 2013 .

In another way the development of the longevity market is providing an echo of the interest rate swaps vs. exchange traded interest futures contracts discussion of the past two decades. And it is a distinction that U.S. regulators are wrestling with in their Dodd-Frank rule-making deliberations. The swaps market is huge and the interest rate

\footnotetext{
18 The U.K. "golden" cohort consists of males aged 75-85; the U.S. "baby boomer" cohort consists of males aged 55-65.

${ }^{19}$ Solvency II is a requirement strictly for insurers, not non-insured pension funds. Any direct influence on those entities will be by example rather than edict.
} 
futures market is small, but the small market is the one showing transparent pricing and zero counterparty risk. The longevity markets may divide along similar lines with a huge, somewhat opaque, swap and insurance market and a smaller (Vita-like and Kortis-like) securities market. It would seem that the Dodd-Frank legislation and its European counterparts are likely to push for more and more price transparency and a lessening of counterparty risk by listing, or at least clearing swaps, at clearing houses.

It is indeed a very exciting time to be considering all the relevant issues in these early days of the potentially huge longevity market.

\title{
Reference
}

Blake, D., Cairns, A.J.G. and Dowd, K. (2006) 'Living with mortality: Mortality bonds and other mortalitylinked securities', British Actuarial Journal 12: 153-228.

\begin{abstract}
About the Author
Morton Lane is the Director of the Master of Science in Financial Engineering (MSFE) Program at the University of Illinois. Dr. Lane also acts as an independent consultant and president of Lane Financial, LLC, a broker-dealer engaged in activity at the intersection of the reinsurance and capital markets. Dr Lane earned his BSocSc from Birmingham University, and his PhD in Mathematics, Business Administration and Computer Science from the University of Texas.
\end{abstract}

